\title{
ФИЛОСОФИЯ
}

УДК 21

DOI: $10.21779 / 2500-1930-2017-32-4-138-150$

\section{К.М. Магомедов}

\section{Религия - теология - наука}

Дагестанский государственный университет; Россия, 367001, г. Махачкала, ул. М. Гаджиева,43a; magomedov49@mail.ru

В статье обсуждаются некоторые методологические проблемы, связанные с включением теологии в реестр научных специальностей, которые активно обсуждаются представителями науки, философии богословия и других отраслей знания. Поднимаются вопросы, важные для утверждения этого нового научного статуса теологии: соотношение религиоведения и теологии, науки и теологии, философии и теологии и другие. Перечисляются некоторые признаки, раскрывающие специфику теологии, ее отличие от других сфер человеческого духа. Приводится широкий исторический и теоретический материал, определяющие становление теологии как научной дисциплины. Анализируются также изменения в функциях науки и теологии, которые происходят после этого решения. Обсуждаются все проблемы с позиции мультикультурализма, предполагающего равноценность всех форм постижения мира и человека.

Ключевые слова: теология, наука, философия, религия, богословие, религиоведение.

Перефразируя известную цитату из классиков марксизма, можно сказать: «призрак бродит по Европе, призрак мультикультурализма», с его отказом от линейной модели взаимодействия различных сфер культуры - мифологии, религии, науки и даже множества отраслей паранауки. Установки постмодернизма хорошо отразили подобный дух сосуществования этих и других составляющих культуры. Отмеченное обстоятельство не могло не сказаться и на самой науке. Началась череда новых и новых поступлений в орбиту научной парадигмы, расширились ее границы, и в ее объектную и предметную сферу вовлекаются звенья, о которых мы раньше и не могли помыслить в качестве таковых. И вот настала очередь теологии. Решением президиума ВАК Министерства образования и науки РФ 12 октября 2015 г. она официально была признана научной дисциплиной и специальностью. В реестре ВАК паспорта научных специальностей, ориентированных на религиознание, до сих пор имели только две специальности: 09.00.13 «Философия и история религии, философская антропология, философия культуры» и 09.00.14 «Философия религии и религиоведение». Теперь такой паспорт приобрела совершенно новая научная специальность 26.00.01. «Теология». Как отмечается в паспорте, данная специальность раскрывает содержание теологии, ее базовые разделы, изучает источники теологического знания, основы вероучения и религиозных обрядов, исторические формы и практическую деятельность религиозной организации, её религиозное служение, религиозное культурное наследие в различных контекстах. Теологические исследования направлены на выявление, анализ и интерпретацию значимых аспектов религиозной жизни и их соотнесение с нормами конкретной религиозной традиции. Важной областью предметного поля специальности «Теология», как отмечается в решении ВАК, является изучение истории и современного состояния отношения религиозной организации к другим конфессиональным учениям и организациям, а также к государству и обществу [18]. 
Несомненно, это свидетельствует о возросшем авторитете религиозного знания всех без исключения конфессий, а главное - о снятии былой противоположности науки и религии.

Появившийся на сайте ВАК приказ Министерства образования и науки России № 927 от 1 августа 2016 г. «Об утверждении состава Экспертного совета Высшей аттестационной комиссии при Министерстве образования и науки Российской Федерации по теологии» знаменует собой новый этап институализации и развития теологии как области знания в современной России.

Экспертный совет ВАК по теологии входят 56 специалистов, по всем областям наук, включенных в корпус теологии согласно принятому паспорту ВАК по этой специальности, и обращенных к исследованию, пожалуй, почти полного спектра традиционных для современной России монотеистических религиозных систем.

Председателем Экспертного совета стал президент РГГУ, доктор исторических наук, профессор и член-корреспондент РАН Ефим Пивовар, историк русского зарубежья и русской эмиграции, председатель Правления Центрального совета Российского общества историков-архивистов.

Отрадно отметить, что в состав этого экспертного совета ВАК вошел и наш земляк доктор философских наук, профессор Билалов М.И., заведующий кафедрой онтологии и теории познания факультета психологии и философии университета, председатель Дагестанского отделения Российского философского общества. Это признание авторитета дагестанской философии, религиоведения, исламской теологии, да и гуманитарной науки в целом.

Но при этом хочется обратить внимание на следующее обстоятельство. Объединенный диссертационный совет по теологии, открытый на базе Общецерковной аспирантуры и докторантуры им. святых равноапостольных Кирилла и Мефодия, Православного Свято-Тихоновского гуманитарного университета, МГУ им. М.В. Ломоносова и Российской академии народного хозяйства и государственной службы при Президенте Российской Федерации, созданный приказом № 601/нк от 30 мая 2016 г., носит, по факту, моноконфессиональный, христианский, а еще точнее, православный характер. Это говорит о некоторой недооценке авторитета исламского религиоведения и мусульманской теологии в структуре российского гуманитарного знания. И это при том, что Председатель ВАК В. Филиппов много раз объявлял, что наука внеконфессиональна, а значит, и теология, раз она объявлена наукой, должна быть именно такой. Думается, что такие моменты - начальная стадия утверждения специальности, и в дальнейшем они должны быть преодолены.

Считаем изложенное важным и потому, что в настоящее время прекращены полномочия специализированного Совета при ДГУ по защите кандидатских и докторских диссертаций, который в прошлом представил на суд научной общественности немало работ именно по религиоведению.

Таким образом, на сегодняшний день имеется возможность представлять к рассмотрению диссертации на соискание ученых степеней кандидата и доктора наук по теологии только по шести отраслям науки, указанным в паспорте научной специальности. Исламской теологии в этом списке, к сожалению, пока нет.

В этом аспекте, присутствие нашего земляка в Экспертном совете по теологии чрезвычайно важно, поскольку необходимо добиваться открытия в республике диссертационного совета по исламской теологии. Для этого у нас есть все данные: и исторические традиции, и научный потенциал, и успешное функционирование уникального, отвечающего всем ВАКовским и иным научным стандартам журнала «Исламоведение». 
Необходимо отметить, что решение о включении теологии в состав научных дисциплин было принято после основательной и достаточно длительной теоретической проработки этого вопроса. Только в «Вопросах философии» было опубликовано несколько работ, посвященных данной теме [3; 19]. Информация о вхождении теологии в разряд научных дисциплин получила неоднозначную оценку у профессионалов и общественности. Многие рассматривают объявление теологии научной дисциплиной как очередной этап в сдаче наукой своих позиций, как очередную уступку религии и чуть ли не как отказ от светской модели российского общества, от конституционно закрепленной нормы об отделении религии и церкви от государства и даже как «возврат к мрачному Средневековью».

Неоднозначно приняли эту информацию также и представители религиозных конфессий и теологии. Одни считают это решение ВАК актом признания религии в качестве неотъемлемого атрибута российского государства, отменой ее «разделенного» статуса со структурами государства. Другие высказывают опасения, что такое признание повлечет за собой подчинение церковного знания светским стандартам и, как следствие, утрату традиционной сакральности.

У специалистов сразу возникает вопрос: зачем нам усложнять и так достаточно сложную иерархию научных дисциплин, ведь уже давно в ней присутствует религиоведение? Разве это не одно и то же? Достаточно только устранить из общественного сознания их противоположную оценку: религиоведения, дающего правильную картину мира, и теологии, выполняющей лишь апологетические функции по отношению к религии.

Нам представляется, что в литературе приводятся достаточно убедительные аргументы в пользу существования теологии в качестве научной дисциплины наряду с религиоведением [17; 21-23].

Нельзя отождествлять теологию и религиоведение (впрочем, как и противопоставлять). Религиоведение всегда имело статус научной специальности. Научная же тарификация теологии в современной мировой культуре началась примерно в 60-е годы прошлого столетия. До этого ни христианская философия, ни какая-нибудь другая теологическая дисциплина в европейских и американских университетах не изучалась и не преподавалась. И это неудивительно, учитывая многолетнее господство в англоязычной философии логического и лингвистического позитивизма, сторонники которого считали религиозные верования не только неверными, но и вообще бессмысленными, не подлежащими серьезному научному дискурсу.

Противопоставление же теологии и религиоведения было оправдано только в условиях монополии атеистического мировоззрения. Тогда никто и не пытался их объединить, поскольку они ставили дихотомические сверхзадачи: первые - выполняли свои апологетические функции обоснования бытия Бога; вторые - стремились показать иллюзорность религиозного постижения мира.

В современных же условиях происходит сближение задач теологии и религиоведения. Статьи по рациональной теологии прочно заняли свое место в структуре публикаций научных журналов. Ведь те и другие ставят перед собой задачу понять разумом то, что раньше было предметом только веры.

Для обоснования правомерности существования теологии наряду с религиоведением попытаемся понять различия между ними. Вот некоторые из них:

- считается, что они выражают различные векторы: теология - внутренний, собственный ракурс, своего рода форму религиозного самопознания; тогда как религиоведение - внешний по отношению к религии аспект. То есть для них существует различный профессиональный тезаурус: теология сама разрабатывает свой собственный ин- 
струментарий познания, тогда как религиоведение изучает эти же вопросы с точки зрения иного внешнего, по отношению к религии, профессионального менталитета;

- если оценивать теологию и религиоведение под углом зрения соотношения их апологетической и познавательной функций, то можно сказать, что в теологии вторая подчиняется первой. Религиоведение же изучает религию как особенную форму постижения мира и человека в нем; поэтому здесь познавательные задачи первенствуют по отношению к апологетическим;

- аналогично, если сравнивать их под углом зрения соотношения векторов познания и спасения, то можно сказать, что в теологии все другие действия, в том числе познавательные, подчинены выполнению этой главной спасительной миссии религии по отношению к обществу и человеку. Как указывается в литературе, богословие изучает те структуры, которыми данное сообщество конституируется в своем своеобразии, в своей претензии на исключительность; речь ведётся о сообществе спасения, которое открывает человеку путь к Богу и жизни в Боге. Познавательный интерес направлен здесь на выявление нормы или идеала религиозной жизни определенной традиции и на рассмотрение человеческой культуры и мира в целом в соотнесении с этой нормой. Религиоведение же интересуется прежде всего не нормой, а реальным религиозным сознанием и реальной деятельностью во всём многообразии их психологических, социальных, культурных и исторических аспектов. Отсюда вывод о необходимом взаимодействии теологии и религиоведения: не зная нормы религиозного сознания данной общины, вряд ли можно здраво судить о формах её реальной религиозности, и наоборот, понимание нормы требует также знания конкретного контекста ее реализации [19, c. 95-96].

- теология и религиоведение отличаются также своими коллективными субъектами; главным субъектом для «церковных» религий, таких, как иудаизм и христианство, теологическим субъектом является церковь. Именно она является основным заказчиком, предметом и местом проведения теологических исследований, хотя в сферу познавательного интереса теологии могут входить иные реалии культурной и общественной жизни. Для нецерковных же структур, таких, как ислам, совокупным субъектом является соответствующий верховный исполнительный и распорядительный его орган, в данном случае - Духовное управление мусульман. Субъектом же религиоведческого дискурса является общество в целом в лице научных, образовательных структур и институтов гражданского общества;

- отсюда следуют существенные текстуальные различия между религиоведением и теологией. Если первое пытается вписать данный текст в более широкий социальный и религиозный контекст, сравнивая ее с постулатами других форм постижения мира и религиозных конфессий, то вторая будет соотносить этот текст, прежде всего, с нормами своего же «ведомственного», т. е. церковного сознания соответствующего уровня.

Сказанное не дает никаких оснований для их противопоставления. Думается, известная теорема К. Геделя о неполноте касается не только аксиоматической теории, как он замыслил; его значение неизмеримо более широко; она действует как норма для взаимоотношения любых теорий, взаимодействуя, они дополняют друг друга. Но вместе с тем необходимо видеть различия между теологией и религиоведением, особенно между их познавательными и образовательными стратегиями. Как отмечает К.М. Антонов в своей интересной статье, в основе различения теологии и религиоведения лежат два различных познавательных замысла, производимое ими знание выполняет разные общественные «заказы», оно опирается на разные, но опять-таки пересекающиеся аспек- 
ты жизненного мира: что Церковь хочет знать о себе и что общество хочет знать о религии [3, с. 74].

Ситуация вокруг современной дискуссии о соотношении науки и теологии, науки и религии напоминает непрерывно идущую в академической среде полемику о специфике философии, об отличиях между наукой и философией. Их полное противопоставление, как и отождествление, не приносит ничего конструктивного в эти сферы человеческого духа; от этого не выигрывает ни наука, ни философия. Но дискуссии, тем не менее, ведутся. При этом называются достаточно существенные отличия философии от науки. Например, выделяются ее черты, как:

- отсутствие у нее строгой, предварительно выделенной предметной области. Это, конечно, не означает беспредметности всей философии. Нет, просто для любого типа философствования такую предметную область предстоит каждый раз обосновать. Если это экзистенциальная философия - это один ее предмет; для позитивистской философии - несколько другой и т. д. М.К. Мамардашвили в своей известной книге «Как я понимаю философию» это очень убедительно показал;

- отмеченная «беспредметность» вытекает из особенностей философии как «знания о всеобщем», как утверждал Гегель. Разве всеобщее можно вместить в «прокрустово ложе» какого-то определенного предмета? Его даже определить толком нельзя, не то что ограничить конкретным предметом. Ведь даже само слово «определить» означает «ограничить пределы» чего-то. Получается, что любое определение в науке неполно. Тем более, это касается философии, выходит, что всеобщее не поддается такому ограничению и определению. Далее, всеобщее не поддается предметному ограничению и определению еще и потому, что они - суть логические операции по выделению некоторых существенных признаков из множества других. Любое явление неизмеримо богаче, чем его определение и сущностная «предметизация». Это вдвойне верно по отношению к философии [14];

- философия как историческая форма мировоззрения, в которой обязательно присутствует субъект, человек. Действительно, любая научная проблема становится философской, как только рассматривается через призму человека. Науку же принято считать системой объективного и закономерного знания, построенного на элиминации, исключении субъекта из познавательного дискурса (гуманитарные науки в данном случае не берутся в расчет). Поэтому, философия - это сфера познавательно-ценностного отношения к миру, что также отличает ее от науки. Отсюда, наука представляет обобщенный, обезличенный взгляд на мир и человека, чего нельзя сказать о философии. Нет философии вообще, а есть философия Платона, Гегеля, моя. Даже в учебниках с коллективным авторством в каждой главе или разделе конкретный автор излагает свое видение проблемы.

Анализ специфики философии в сравнении с наукой, конечно, можно продолжить. Исходя из этих и других отличий философии от науки, никто не ставит под сомнение ее научность.

Примерно таким должно быть отношение и к теологии. Конечно, было бы несправедливо все содержание теологии относить к научной проблематике. Подобно тому, как мы в любой науке выделяем теоретическую и прикладную составляющие, в теологии также необходимо выделять два уровня. Как отмечается в литературе, в рамках систематической теологической рефлексии следует различать: 1) общую систематическую рефлексию относительно форм богочеловеческого отношения, реализующихся в данной общине; 2) поддерживающую ее совокупность образовательных структур и научных исследований. Для первой характерно специфическое сочетание богопознания 
и исповедания: мышления, уясняющего положение человека в отношении к Богу и миру, и проясняющего возвещение истин веры, указывающих человеку путь к спасению. От второй, напротив, требуется максимально точное и в каком-то смысле «бездумное» исполнение определенного набора процедур, нацеленных на получение конкретного частного результата: решения определенной научной проблемы [15]. Первые представляют собой прикладные вопросы теологического знания; вторые же - рефлексию основных вопросов богопознания, поэтому с полным основанием могут и должны быть включены в состав научной теологии.

Напрашивается еще одна сравнительная параллель между философией и теологией. Одна из главных функций философии по отношению к науке, как известно, методологическая. Она обеспечивает процесс «комфортного» вхождения той или иной научной парадигмы в существующую картину мира, процесса, который часто протекает болезненно и противоречиво. Примеры включения теории относительности, квантовой физики или генетики в научную картину мира подтверждают этот тезис.

Нам представляется, такую же функцию, какую философия выполняет по отношению к науке, теология выполняет по отношению к религии: она обеспечивает более или менее комфортное вхождение религии в существующую культуру. Она - своего рода посредник между религией и культурой.

Когда речь идет о теологии в структуре научного познания, не следует забывать, что речь идет не о религии, а о теологии, направленной на изучение особенных религиозных рациональных механизмов постижения мира. В этом плане теология всегда, с момента своего формирования и на протяжении всей истории, правда, с разным успехом была вовлечена в орбиту научного знания и философского осмысления. Так что хотим успокоить всех, особенно представителей радикального сциентизма и антисциентизма, а также тех, кто воспитан в духе воинствующего атеизма: свободе совести ничто пока не угрожает и конституционные нормы, регламентирующие взаимодействие общества и религии, науки, образования и религии, продолжают оставаться незыблемыми.

Поражаешься, как часто в истории порой радикально меняется менталитет человечества и даже одного народа! Казалось бы, только недавно, в обозримом историческом прошлом, в европейском сознании ситуация была обратной: соответствие науки духу и букве божественного откровения служило главным критерием ее научности. Затем, начиная с идеологии вольтеровского Просвещения, наступает длительная эра безбожия и атеизма. А сейчас, говоря гегелевским языком, происходит «возврат якобы к исходному», формируя постмодернистскую культуру симультанности, одновременности и равноценности различных форм постижения мира.

Сразу возникает вопрос, почему у нас собственно возникает какой-то полемический настрой после подобных сообщений об изменениях модусов взаимодействия науки и религии? Ведь на Западе она уже давно и прочно входит в реестр научных дисциплин и преподается в качестве учебной специальности со своей методологией и методикой. Поэтому из такого соседства науки и теологии там особую проблему не делают. И это происходит в странах, где позитивистские и сциентистские тенденции были особенно сильны. Это, нам представляется, объясняется несколькими причинами:

- во-первых, нашим коммунистическим и атеистическим прошлым, когда целые поколения людей были воспитаны в духе воинствующего атеизма, из чего вытекала установка о принципиальной ненаучности и вненаучности теологии;

- во-вторых, традиционная наука была ограничена методологическим натурализмом, ориентированным на постижение природы, исходя из нее самой; она считала, что 
ученому вообще непозволительно ссылаться на что-то другое, в т. ч. на Бога, как в самой теории, так и в интерпретации ее данных. Следовательно, наука - это совершенно отличная от теологии и религии сфера рационально-понятийного постижения мира.

- в-третьих, спецификой православной и исламской культур, как преимущественно «антисциентистских» по своему духу. В отличие от католицизма, где давно и прочно утвердился принцип гармонии и веры в различных исторических модификациях, они только сейчас вовлекаются в орбиту рационального осмысления своих постулатов;

- в-четвертых, все без исключения исторические формы позитивизма надолго и всерьез направили религию и науку по противоположным векторам взаимодействия. Вначале в классическом позитивизме все суждения, которые не подходят под верификационные критерии, были объявлены вненаучными. Это, прежде всего, касалось религии и философии. Они, если и имеют какое-то значение, то скорее эстетическое, символическое. Поэтому первая и вторая волны эмансипации науки должны были освободить науки именно от религии и философии. Неопозитивизм пошел дальше, объявив их языковыми, логико-синтаксическими конструкциями, также не имеющими научнопознавательной ценности. Даже эстетическая ценность их незначительна; как отмечал Р. Карнап, они как «метафизика - музыканты без музыкальных способностей» [10, c. 26]. Представители критического рационализма в лице К. Поппера и других продолжили эту тональность, объявив религиозные суждения бессмысленными и неопровергаемыми.

Нельзя сказать, что такая дихотомичность в отношениях религии и науки была характерна только для исторического прошлого. И в современной культуре также существует весьма серьезная оппозиция религии и науки. Атеизм как мировоззренческая установка, продолжает существовать и приобретает новые, более корректные, формы. Скажем, представители так называемого «нового атеизма» в лице Ричарда Докинза, Даниэля Денкетта, Кристофера Хитченса, Сэма Харриса, Дж. Серла, Ричарда Рорти и других рассматривают науку как эффективный инструмент борьбы с религией. Например, Докинз в нашумевшей книге «Бог как иллюзия» приводит следующий атеистический аргумент: если Бог существует, то он должен быть крайне высокоорганизованным и сложным, а эти качества и вероятность находятся в отношениях обратно пропорциональной зависимости; чем более сложным является объект, тем меньше вероятность, что он существует. Следовательно, идея всеобщего и всемогущего Бога является иллюзией [9].

Нам представляется, что аргументы противников включения теологии в реестр научных дисциплин не совсем корректны по следующим соображениям:

1. Простой перенос научной метрики измерения мира на сверхъестественные процессы мало что дает и часто приводит к абсурду. Приведенный пример из работы Докинза, подтверждает данный тезис. Это в реальном бытии чем сложнее объект, тем больше у него частей. (И то не всегда, например, в квантово-механических процессах вообще нельзя мыслить понятиями «шире - уже», «целое - часть»). Да и вообще, оценивать Бога мерками сложности в принципе неточно: с таким же успехом можно сказать, что Бог являет собой наипростейшее бытие, и это будет правильно. Вспомним в связи с этим некоторые положения учения Николая Кузанского о Боге как бесконечности. Бесконечное нельзя постигнуть через конечное. Любая часть его также есть бесконечность, абсолютный минимум и абсолютный максимум в бесконечности совпадают, т. е. в ней противоположности тождественны.

2. Не надо забывать о том, что в реестр научных дисциплин входят не только естественные и логико-математические науки, которые, возможно, действительно дале- 
ки от теологии, но и гуманитарные, стандарты которых неотделимы от сверхъестественного, символического видения мира [13]. В наличии общих точек пересечения у гуманитарных наук и теологии не приходится сомневаться (Но, поскольку этот вопрос является предметом подробного самостоятельного анализа, мы опускаем его).

3. Сближение теологии и науки - это улица с двусторонним движением; следовательно, «на встречном курсе» предполагается взаимное сближение науки и религии. Речь здесь идет не только о всевозможных доказательствах бытия Бога, с использованием научного инструментария, не столько о необходимости применения. Для этого научных аргументов, сколько об использовании ее методологии. Речь не только о том, что религия и теология уже давно используют аргументы разума и доказательства, но и о движении науки к религии, к выполняемым ею функциям. Получается, что известная формула: «Богу богово, а кесарю кесарево» в отношении науки и религии сейчас не работает.

Таким образом, формируется совершенно новая модель взаимодействия теологии и науки, свободная от крайностей сциентизма и антисциентизма, «высокомерия» по отношению к одной из них, как это не раз бывало в истории.

Присущая нашему мышлению «маятниковость», переходы из одной крайности в другую часто отражались и на отношениях религии и науки. Ведь не секрет, что в истории религия и его церковь часто подчиняли себе науку, представляя себя единственными носителями истинного знания. Но не реже бывало и обратное, когда наука подчиняла себе религию и теологию. Как отмечает Ю.В. Горбатова, в современных условиях наука вольно или невольно во многом присвоила себе функции, которые в традиционном обществе выполняет религия, первостепенную ценность имеет лишь то, что может быть рационально (научно) обосновано. Религия, какое бы влияние она ни имела на умы своих последователей, остается «за бортом» научного мэйнстрима. Исследования Плантинги возвращают не только надежду, но и уверенность в том, что теология имеет под собой твердую (читай: рациональную) почву. Таким образом, теология становится вровень с современной наукой, возвращает себе права, которыми когда-то обладала, но уже на других основаниях - тех, что принимаются современным обществом как легитимные [6, с. 152].

Формулируется даже призыв к теологам вообще отказаться от своих апологетических функций как неэффективных, поскольку в соответствии с современной реформистской эпистемологией все доказательства, приводимые посредством дискурсивных рассуждений, вытекают не из глубин веры, а из иной, даже конкурирующей с верой, методологии [3].

Включение теологии в реестр научных специальностей влечет за собой появление дополнительных обязательств как перед наукой, так и перед теологией. Наука должна снять многие, негативно окрашенные тона профессионального «высокомерия» во взаимоотношениях с теологией; стратегия мультикультурализма требует также упразднения дихотомичности мышления, построенного исключительно на законах формальной логики с ее законом «исключенного третьего», направляющего мышление на одномерное видение мира с одной единственной матрицей истинности.

Теология также, не изменяя своей сути, должна признать соответствующие «правила игры», принятые в научном тезаурусе: определенные требования к степени достоверности и непротиворечивости знания; свобода мышления и дискуссий; открытость и незавершенность любого знания; должная верификация данных (если не экспериментальная, то хотя бы через неспециализированный опыт человечества или конкретного народа); действие «фальсификационного» критерия научности обоснованного К. Поп- 
пером, определенная формализация содержательного материала и др. Без принятия теологией этих и других критериев научности, вхождение ее в реестр научных специальностей будет только на словах, а не на деле.

Естественно, речь здесь не идет о механическом переносе научной методологии на религиозный материал; этого не нужно делать, пожалуй, это и невозможно. Отмеченные механизмы научного познания должны преломляться в теологии специфическим образом.

Для примера рассмотрим такой важный метод научного познания, как формализация. Понятно, в теологии этот метод используется не в духе современного логического позитивизма через использование аппарата математической логики. Религиозный опыт во многом является мистическим и по этой причине трудно поддается категориализации и формализации.

Здесь имеется в виду переработка всех норм религиозного сознания в такие формы, в которых они становятся общедоступными для научного изучения. Для этого многообразный и неформализуемый в полной мере религиозный опыт, изучаемый, скажем, в патрологии, аскетике или любой другой богословской отрасли, должен обобщаться, чтобы стать источником для научной методологии.

В свете сказанного становится совершенно очевидно, что степень этого самого обобщения в науке, теологии и религии в существенной степени различается. Общедоступность изучаемого религиозного явления для всех представителей исследовательского сообщества в науке предполагает, что оно должно быть понято, если не принято, всеми: и теми, кто разделяет данное мировоззрение, и теми, кто не разделяет. Как справедливо отмечается в литературе, применительно к христианству требование научности предполагает, что верующие основывают норму своего религиозного сознания на Божественном Откровении, с результатами формализации которого ими и будет проводиться процедура богословского соотнесения. Но в отношении тех, кто не разделяет религиозного мировоззрения, нельзя говорить не только о нормативности такой процедуры, но и вообще о факте признания самого Откровения. Именно поэтому соотнесение изучаемого богословским методом явления должно проводиться по отношению не к самому Откровению, а к результатам осуществлённой в рамках конкретной богословской традиции формализации нормы религиозного сознания. Можно не признавать ревеляционизм, но нельзя отрицать факта существования Священного Писания, корпуса святоотеческих творений, литургической традиции, то есть всего того, что является зафиксированной в материальных носителях нормой религиозного сознания, влияющей на жизнь, поведение и культуру человечества [19].

Это сближение науки и религии должно происходить не за счет отказа от своей предметности и содержания, а за счет трансформации языка, логических и рациональных средств аргументации. Как отмечает академик В.А. Смирнов, прежде всего должен радикальным образом измениться вектор онтологической проблематики в философии и теологии. Они уже должны решаться не в рамках натурфилософии и не только естественнонаучными методами, но и путем анализа познавательных процедур и категориальной структуры мышления. Особое внимание в современной онтологии должно уделяться тому (как правило - искусственному) языку, с помощью которого осуществляется анализ, поскольку ни выбор этого языка, ни сам язык, ни средства этого языка, с помощью которых будет осуществляться анализ, не безразличны к объекту исследования: выбранный язык вынуждает принять определенную онтологию. В силу этого одна из задач современной философии состоит в том, «чтобы установить связь между принимаемыми средствами выражения и рассуждения, с одной стороны, и допущениями об 
объектах рассуждения - с другой. И не только описать, но и четко сформулировать и обосновать. Конструирование искусственных языков и выяснение содержащихся в них онтологических допущений является хорошим средством изучения проблем онтологии» [20, с. 144].

В 1980 г. в журнале «Тайм» вышла заметка «Modernizing the casefor God», в которой указывалось, что «в результате тихой революции в мышлении и аргументах, которую едва ли мог кто-нибудь предвидеть пару десятилетий назад, Бог возвращается. Наиболее примечательно то, что это происходит не среди теологов и простых верующих, а в интеллектуальных кругах академических философов, в которых Всемогущий единодушно надолго был изгнан из сферы плодотворного дискурса» [16].

Кстати, в этой же статье отмечается ведущая роль Алвина Плантинги в становлении новой модели взаимодействия науки и теологии в рамках так называемой аналитической теологии, у истоков которой он стоял. Согласно последней религия не может существовать в прежней классической и фундаменталистской форме, она должна подвергнуться модернизации. Для этого она должна стать на путь рационализации своих постулатов.

Этот процесс дефундаментализации и рационализации теологии был начат кальвинистской религиозной философией, сторонники которой исходили из трех положений:

- во-первых, теист, который считает веру в Бога базисной, т. е. не нуждающейся в обосновании, не нарушает никакой познавательной нормы;

- во-вторых, нельзя также считать веру в Бога иррациональной, если ее считают базисной в указанном смысле. Следовательно, вера, не опирающаяся на обоснования, не свидетельствует о дефектах в познавательной деятельности;

- в-третьих, вера в Бога, опирающаяся на обоснования и свидетельства, не превосходит в познавательном отношении веру, воспринимаемую как нечто базисное.

Следовательно, вера в Бога, заключает Плантинга, не нуждается в свидетельской поддержке из каких-то других источников, каких-то других верований для того, чтобы считаться рациональной.

Согласно Плантинге, обвинение теизма в иррационализме никак не обосновано; аналогичным образом можно обвинить сторонников всех иных форм постижения мира: «Вера в существование Бога находится в одинаковых условиях с верой в существование других сознаний, прошлого, чувственно воспринимаемых предметов» - у нас нет убедительных доказательств в пользу всех этих верований, но отсюда не следует, что придерживаться их иррационально [2, с. 12]. Как отмечается в литературе, точка зрения Плантинги вызывает существенные возражения методологического порядка, поскольку концепция «базисности» религиозных верований полностью зависит от того, какой характер носит эта самая базисность. Сами критерии базисности являются весьма расплывчатыми. Все дело в том, полагается ли эта базисность каждый раз теми или иными носителями религиозных верований, или предлагаются какие-то объективные эпистемологические основания для того, чтобы считать эти верования базисными. Если такие основания не представлены и все сводится к субъективному полаганию религиозных верований в качестве базисных, т. е. несводимых к другим, а потому неуязвимых для критики с позиций других верований, то мы имеем дело с новой формой фидеизма. Следует отметить, что в рассуждениях Плантинги нет ясности относительно того, понимает он базисность религиозных верований в смысле субъективной достоверности и рациональности или в смысле их эпистемологической автономности [22]. 
Плантинга оказался у истоков еще одной «модной» дисциплины, возникшей совсем недавно, в 90-х годах прошлого века, и находящейся на стыке науки, теологии и психологии - когнитивного религиоведения. Одна из первых проблем, обсуждаемых в рамках этой дисциплины, - это концепт sensus divinatus («чувство Божественного»). Масштабные эксперименты с детьми и взрослыми показали, что врожденные особенности психики предрасполагают нас к религиозности. Например, для маленьких детей, вне всякой зависимости от их культурного окружения, представления о всемогущих и вездесущих существах являются естественными, а от мысли, что природные объекты были «задуманы» кем-то с определенной целью, не могут до конца абстрагироваться даже убежденные атеисты. Поэтому религия не есть форма иллюзорного постижения мира, навязанная извне, тем более, она не есть «опиум для народа» и «род духовной сивухи» для человека.

В российской философской литературе исследованию концептуальных основ аналитической теологии как целостного философского направления уделяется достаточно внимания (монография Кимелева Ю.А., некоторые статьи Горбатовой Ю.В., Карпова К.В., Бородина Ф.Ю. и другие [12; 5; 6; 7; 11], защищены диссертации [8]).

Этимология слова, обозначающего предмет какой-то науки, вовсе не определяет ее содержание, тем более в современном понимании. Ведь исходя из «философии» как любви к мудрости, никто из философов сейчас не будет претендовать на монополию на обретение заветной мудрости. Последняя вообще не может быть профессиональной; она больше от жизни, чем от знания. Из того, что психология была отнесена Аристотелем к наукам о душе, никто не будет таким образом понимать предмет современной психологии.

Теология в этом ряду - не исключение; она также предметно видоизменяется. У Аристотеля теология - наука о высшем - «существующем самостоятельно и неподвижном», «о сущем, как сущем», являющаяся наивысшей составляющей «умозрительного» знания, тождественной первой философии [4, т. 1, с. 182].

У Фомы Аквинского теология есть наука «о Боге и всех вещах в их отношении к Богу» [1, с. 12]. В целом, конечно, правильно, но в подобных определениях, во-первых, нет diferentia specifika, т. е. выделения отличительного признака. Поэтому из них не видно отличия теологии от религии. Во-вторых, обоснование бытия Бога и определенного отношения к нему - это задача не всей теологии, а лишь одного из ее разделов апологетики. Современный подход к предмету теологии предполагает достаточно четкое осознание ее специфики. В ее задачу входит уже не входит «прямое усмотрение» Бога, что является основной функцией религии, а понимание Бога рациональными средствами.

Еще одно, как мы считаем, своеобразие науки и теологии. Вспомним, что в качестве важнейшего критерия демаркации естественных и гуманитарных наук, в методологии науки всегда приводятся сравнительные различия механизмов объяснения и понимания. В целом, если исключить нюансы такого вопроса и условность этого деления, то можно сказать, что в гуманитарных сферах доминируют инструменты понимания. (Сразу вспоминаются знаменитые кинофильмы моего поколения «Доживем до понедельника», где мальчик в сочинении на свободную тему написал: «Счастье - это когда тебя понимают»; и современная картина Валерии Гай Германики «Школа» о драматургии взаимного непонимания детей, родителей, учителей, да и самих себя).

Так вот, нам представляется, что теологический дискурс всегда имеет такую герменевтическую направленность, где также доминируют механизмы понимания. В статье Польскова К.О., которую мы уже цитировали, подробно раскрывается этот вопрос. 
Всю теологическую герменевтическую методологию он разделяет на три составные части: 1. Методы библейской герменевтики; 2. Методы святоотеческой герменевтики; 3. Методы церковно-исторической герменевтики. Данное деление, как отмечает автор, не нарушает целостности единого богословского метода. Эта целостность является его существенным свойством. Священное Писание воспринимается в контексте определенной церковно-исторической традиции, но при этом сама традиция во многом формируется в результате интерпретации Писания. Все три разновидности богословского метода не находятся друг по отношению к другу в отношении часть/целое. Как и в случае с движением мысли по типу герменевтического круга, повторное возвращение от одной к другой меняет и углубляет понимание смысла целого, превращая его в динамический процесс [19, с. 93-101].

Мы рассмотрели некоторые методологические вопросы, без выяснения которых невозможно утверждение теологии как научной дисциплины. При этом отдаем себе отчет, что она только начинает в этом качестве утверждаться. Поэтому уверены, что в дальнейшем появятся серьезные публикации на эту тему.

\section{Литература}

1. Аквинский Ф. Сумма теологии. - М., 2006.

2. Аналитический текст. Антология Алвина Плантинги / сост. Джеймс Ф. Сенней; пер. с анг. К.В. Карпова; под ред. В.К. Шохина. - М.: Языки славянской культуры, 2014.

3. Антонов К.M. Теология как научная специальность // Вопросы философии. 2012. - № 6. - C. 73-84.

4. Аристотель. Сочинения: в 4 т. - М.: Мысль, 1975.

5. Бородин Ф.Ю. «Реформистская эпистемология» в истории аналитической философии религии // Universitas: Наука в контексте современной культуры: междисциплинарный сборник научных трудов молодых ученых СПбГУ. - СПб., 2001. - С. 13-24.

6. Горбатова Ю.В. Алвин Плантинга о космологическом доказательстве бытия Бога святого Фомы Аквинского. Критический обзор некоторых аспектов // Вопросы философии. - 2011. - № 1. - С. 150-159.

7. Горбатова Ю.В. Плантинга и его модальная версия онтологического доказательства // История философии. - 2012. - № 17. - С. 243-261.

8. Горбатова Ю.В. Логико-онтологические основания современной аналитической теологии (на материале концепции Алвина Плантинги): автореф. дис. ... к. филол. н. 09.00.01. - М., 2012. - 46 c.

9. Докинз Р. Бог как иллюзия. - М.: Азбука - Артикус, КоЛибри, 2016.

10. Карнап P. Преодоление метафизики логическим анализом языка // Вестник Московского университета. Сер. 7: Философия. -1993. - № 6. - С. 20-51.

11. Карпов К.В. Эпистемологические предпосылки теистической философии А. Плантинги // Вестник ПСТГУ І: Богословие. Философия. - 2014. - Вып. 4 (54). - С. 64-79.

12. Кимелев Ю.А. Современная западная философия религии. - М.: Мысль, 1989.

13. Кохановский В.П. Философские проблемы социально-гуманитарных наук: учебное пособие для аспирантов. - Ростов н/Д: Феникс, 2005.

14. Магомедов К.М., Билалов М.И. Специфика философии, о разных логиках и о границах применения информационных технологий в учебном процессе // Вестник Дагестанскогогосударственного университета. - 2012. - № 6. - С. 101-109. 
15. Месяи C.B. Понятие QEOLOGIA в античной философии // Философия религии: альманах. 2006-2007. - М., 2007. - С. 228-246.

16. Modernizing the Case for God // Time. - 1980. - 5 April.

17. Овсиенко Ф.Г. Сферы изысканий религиоведения и теологии и специфика постижения ими рассматриваемых объектов // Религиоведение. - 2004. - № 2. - С. 116130 .

18. Паспорта научных специальностей //vak.ed.gov.ru/316.

19. Польсков К.О. К вопросу о научном богословском методе // Вопросы философии. - 2010. - №7. - С. 93-101.

20. Смирнов B.A. Логические методы анализа научного познания. - М.: Эдиториал УРСС, 2002.

21. Элбакян E.C. Религиоведение и теология: к проблеме демаркации объектов исследования // Религиоведение. - 2001. - № 1. - С. 110-116.

22. Элбакян E.C. Профанная теология или профанация науки? /http://www.religiopolis.org/index.php/publications/81-profannaja-teologija-ili-profanatsijanauki.

23. http://www.soctheol.ru/religion/planting_i_ego_proekty.

Поступила в редакиџио 28 апреля 2017 г.

UDC 21

DOI: $10.21779 / 2500-1930-2017-32-4-138-150$

\section{Religion - theology - science}

\section{K.M. Magomedov}

Dagestan State University; Russia, 367001, Makhachkala, M. Gadzhiev st., 43a; magomedov49@mail.ru

The article runs about some of the methodological issues associated with the inclusion of theology in the register of scientific specializations that are being actively discussed by representatives of science, philosophy, theology and other disciplines. The issues that are important for the approval of this new scientific status of theology are the ratio of religious studies and theology, science and theology, philosophy and theology and others. Some signs disclosing specifics of theology, her difference from other spheres of human spirit are listed. Wide historical and theoretical material, defining formation of theology as scientific discipline is given. Also changes in functions of science and theology which happen after this decision are analyzed. All problems from a position of the multiculturalism assuming equivalence of all forms of comprehension of the world and the person are discussed.

Keywords: theology, science, philosophy, religion, theology, religious studies.

Received 28 April, 2017 